\title{
Design of a Corporate fed $1 \times 2$ Microstrip Array Antenna for X Band Applications
}

\author{
Dilip Singh Rawat \\ ECE Department \\ Bipin Tripathi Kumaon Institute \\ of Technology \\ Dwarahat, Almora, India
}

\author{
Gaurav Singh \\ ECE Department \\ Bipin Tripathi Kumaon Institute \\ of Technology \\ Dwarahat, Almora, India
}

\author{
R P Singh \\ ECE Department \\ Bipin Tripathi Kumaon Institute \\ of Technology \\ Dwarahat, Almora, India
}

\begin{abstract}
This article presents a simple $1 \times 2$ Rectangular microstrip array antenna fed by corporate feed network. The array is designed to operate in X Band using FR4 as Substrate with permittivity, $\varepsilon_{\mathrm{r}}=4.4$ and height, $\mathrm{h}=1.66 \mathrm{~mm}$. The proposed array antenna has dual band characteristics. The parameters of the antenna are selected to achieve the compact dimension. The designed array antenna is simulated using HFSS v12 simulator and simulation results are shown in terms of return loss, VSWR, radiation pattern and gain are presented. The results show that the antenna has dual band characteristics with the overall impedance bandwidth (VSWR $\leq 2$ ) of about $20.52 \%$. The proposed antenna array is suitable for applications such as Satellite communication, Radar and other Wireless systems.
\end{abstract}

\section{Keywords}

Microstrip Antenna, Dual band, Array antenna, corporate feed network, HFSS.

\section{INTRODUCTION}

Microstrip antennas are currently the most dynamic fields of Antenna theory. A microstrip antenna consists of a metallic patch printed on a thin, grounded dielectric substrate. Advantages of microstrip antennas include light weightiness, reduced size, low cost, conformability and the ease of integration with active device. However they suffer from disadvantages such as narrow bandwidth, poor polarization purity, low power, spurious feed radiation etc [1]. Therefore, the challenge in microstrip antenna design is to increase the bandwidth and gain [2].

Different array configuration of microstrip antenna can be used to overcome low gain, narrow bandwidth and low power handling capacity of the single element. To make this array an effective radiator, individual patch has to be suitably fed [3] [4]. The feed arrangement can be single line or multiple lines. Single line feed is known as series feed network and multiple feed line is known as corporate feed network. Power distribution among antenna elements can be modified by corporate feed network. The corporate feed network can steer beam by introducing phase change [5].

In 2006, two element rectangular microstrip array antenna fed by corporate fed technique with the impedance bandwidth of $220 \mathrm{MHz}$ is presented by Konda et al [6]. In 2009, Mallikarjun et al. presented a two element rectangular microstrip array antenna with a new approach in feed network design and achieved impedance bandwidth of $1340 \mathrm{MHz}$ [7].
The proposed antenna array has dual band characteristics. The simulation is performed by using HFSS v12 and it shows the results in terms of return loss, VSWR, impedance bandwidth and radiation pattern. The simulation results of the antenna array are compared with the experimental results [7]. The results shows that the array has dual band characteristics and because of the dual band the overall impedance bandwidth of the array is improved. When the operating frequencies are far apart the array structure can be conceived to avoid the use of separate antennas [8]. The proposed antenna array is suitable for applications such as Satellite communication, Radar systems and other modern communication systems.

\section{ANTENNA CONFIGURATION}

The antenna is designed using FR4 material with thickness of $\mathrm{h}=1.66 \mathrm{~mm}$ and relative permittivity of $\mathrm{Er}=4.4$. The elements of the array are designed for $9.2 \mathrm{GHz}$. The antenna elements are fed using the corporate feed technique. This technique is simple and can be simultaneously fabricated along with the antenna elements [9]. The design of array with corporate feed network is shown in Fig. 1. The two array elements are kept at a distance of $27.9 \mathrm{~mm}$ from their center point. This optimized distance is selected in order add the radiated power in free space and achieve minimum side lobes in radiation pattern [1]. Various dimensions of patch, ground plane and corporate feed line network are given in table 1 .

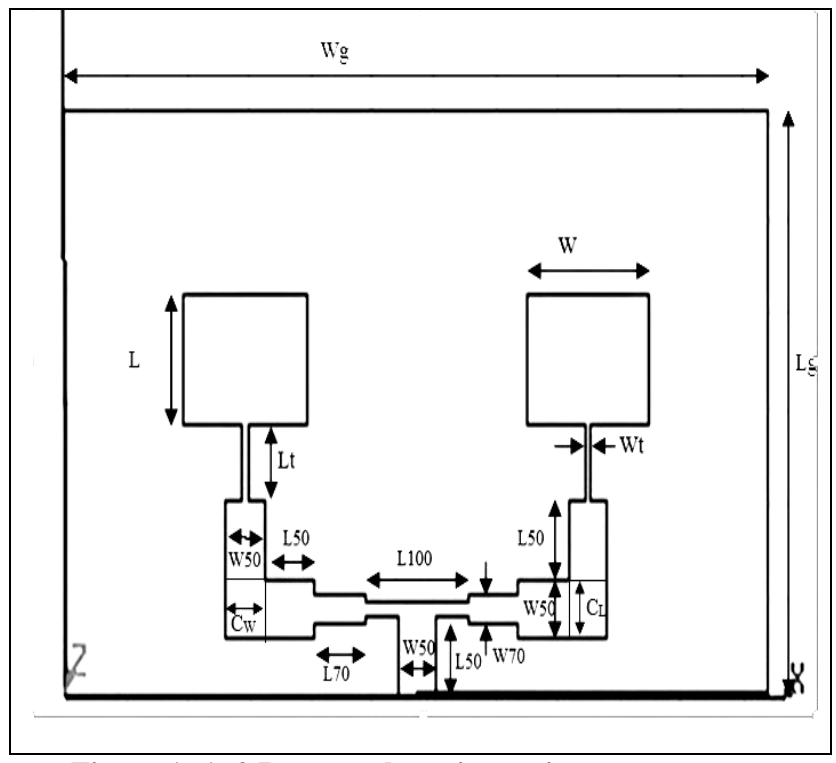

Figure 1-1×2 Rectangular microstrip array antenna 
TABLE - 1

\begin{tabular}{|l|l|}
\hline (a)Patch Dimensions: & \\
\hline Length of the Patch(L) $(\mathrm{L})$ & $6.8 \mathrm{~mm}$ \\
\hline Width of the Patch(W) & $9.9 \mathrm{~mm}$ \\
\hline Distance between the two driven elements(D) & $27.9 \mathrm{~mm}$ \\
\hline (b)Ground Plane Dimensions: & \\
\hline Length of the ground plane $\left(\mathrm{L}_{\mathrm{g}}\right)$ & $30.6 \mathrm{~mm}$ \\
\hline With of the ground plane $\left(\mathrm{W}_{\mathrm{g}}\right)$ & $57 \mathrm{~mm}$ \\
\hline (c)Corporate Feed Line Dimensions: & \\
\hline Length of $50 \Omega$ line $\left(\mathrm{L}_{50}\right)$ & $4.1 \mathrm{~mm}$ \\
\hline Width of $50 \Omega$ line $\left(\mathrm{W}_{50}\right)$ & $3.1 \mathrm{~mm}$ \\
\hline Length of $100 \Omega$ line $\left(\mathrm{L}_{100}\right)$ & $8.3 \mathrm{~mm}$ \\
\hline Width of $100 \Omega$ line $\left(\mathrm{W}_{100}\right)$ & $0.7 \mathrm{~mm}$ \\
\hline Length of $70 \Omega$ line $\left(\mathrm{L}_{70}\right)$ & $4.1 \mathrm{~mm}$ \\
\hline Width of $70 \Omega$ line $\left(\mathrm{W}_{70}\right)$ & $1.6 \mathrm{~mm}$ \\
\hline Length of Coupler( $\left.\mathrm{C}_{\mathrm{L}}\right)$ & $3.1 \mathrm{~mm}$ \\
\hline Width of the Coupler $\left(\mathrm{C}_{\mathrm{w}}\right)$ & $3.1 \mathrm{~mm}$ \\
\hline Length of Quarter wave transformer $\left(\mathrm{L}_{\mathrm{t}}\right)$ & \\
\hline Width of the Quarter wave transformer $\left(\mathrm{W}_{\mathrm{t}}\right)$ & \\
\hline
\end{tabular}

\section{RESULTS AND DISCUSSION}

The Designed array is simulated using Ansoft HFSS v12 simulator. This was used to calculate the return loss, impedance bandwidth and radiation pattern.

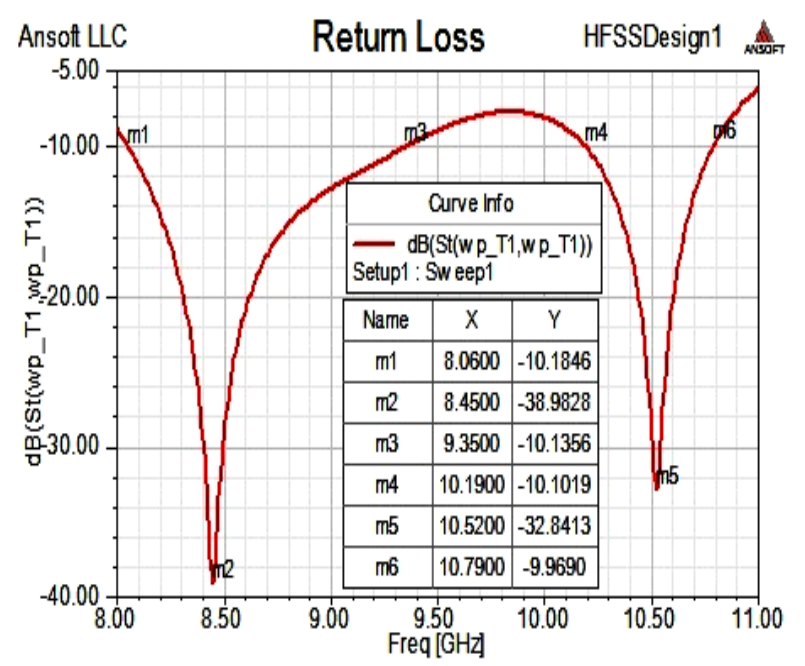

Figure 2-Return loss of array antenna

The Return Loss of the antenna at $8.45 \mathrm{Ghz}$ is $-38 \mathrm{~dB}$ and at $10.52 \mathrm{Ghz}$ is $-32 \mathrm{~dB}$. Hence, antenna has good return loss.

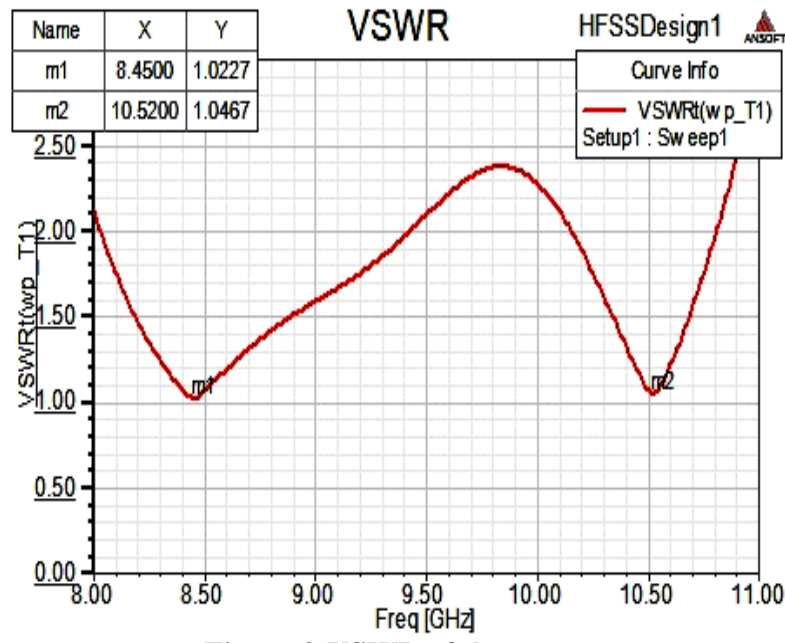

Figure 3-VSWR of the array antenna

The VSWR of the antenna at $8.45 \mathrm{Ghz}$ is 1.02 and at 10.52 $\mathrm{Ghz}$ is $1.07 \mathrm{~dB}$ which is less than $2 \mathrm{~dB}$. Hence, antenna is properly radiating.

\section{Ansoft LLC Radiation Pattern 2 HFSSDesign1 슬}

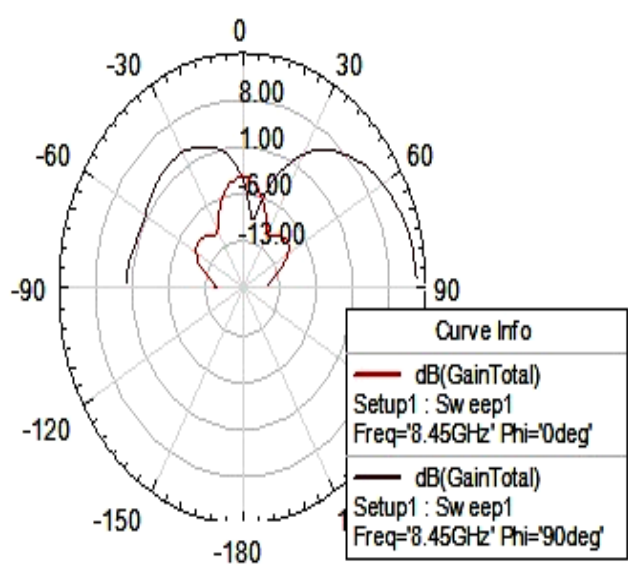

(a) Frequency $=8.45 \mathrm{GHz}$

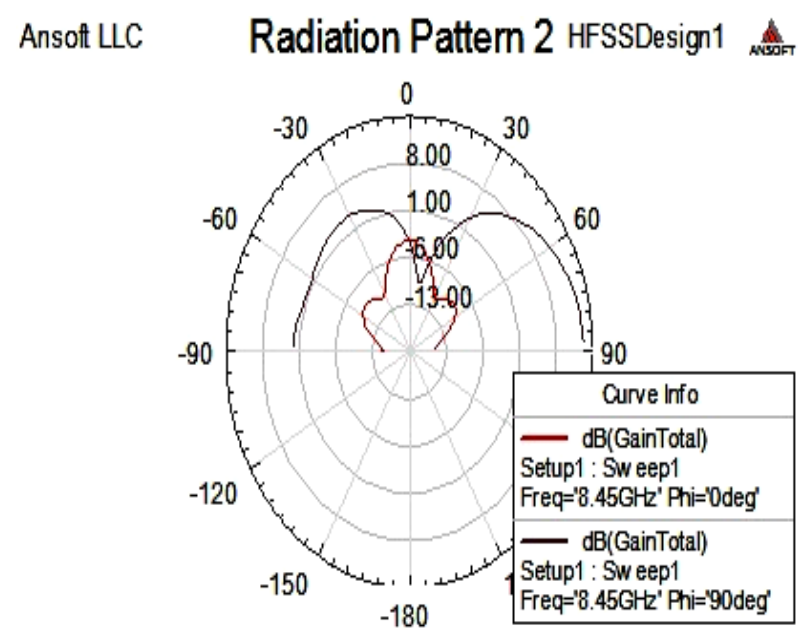

(b) Frequency $10.52 \mathrm{GHz}$

Figure 4-Radiation pattern of the Array antenna 


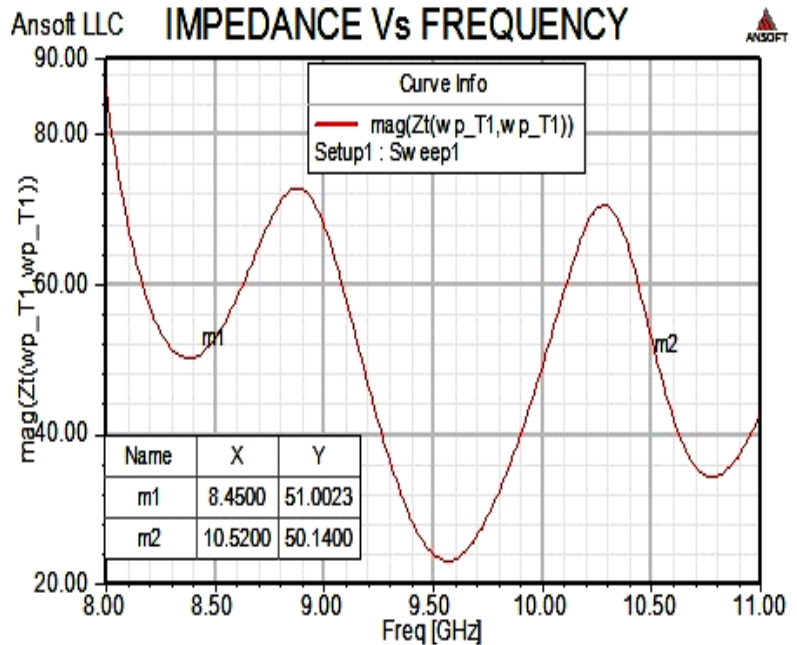

Figure 5-Impedance versus Frequency of array antenna

The impedance bandwidth over return loss less than $-10 \mathrm{~dB}$ for the proposed antenna is shown in figure 2. The simulation result shows that antenna resonates at $8.45 \mathrm{GHz}$ and 10.52 $\mathrm{GHz}$ and two bands of (BW1, BW2), each of magnitude 1290 $\mathrm{MHz}$ and $600 \mathrm{MHz}$ are obtained. So the overall impedance bandwidth of the array is $1890 \mathrm{MHz}$ i.e. $20.52 \%$. The VSWR obtained at the resonating frequency is 1.022 and 1.046 respectively as shown in figure 3 . The radiation pattern of the antenna is shown in figure $4 \mathrm{a}$ and $4 \mathrm{~b}$. The gain of the array is $8.86 \mathrm{~dB}$. Impedance versus frequency graph shows that at resonating frequency the impedance of the feed is matched as shown in figure 5 .

\section{CONCLUSION}

The proposed array is very simple and uses low cost substrate material. Corporate feed network is used and it can be simultaneously fabricated along with the antenna elements. The array shows dual band characteristics so the array structure can be conceived to avoid the use of separate antennas. The simulation results are shown in terms of return loss, VSWR, radiation pattern and gain. Good results for return loss, VSWR, Gain and the radiation characteristics of this array have been achieved. The proposed array can be used for X Band applications such as Satellite communication, Radar systems and other modern Wireless systems.

\section{REFERENCES}

[1] C. A. Balanis, Antenna Theory- Analysis and Design, 3rd ed., John Willey and \& Son, Inc., 1997.

[2] R. J. Mailloux, J. F. McIlvenna, and N. P. Kernweis, "Microstrip Array Technology," IEEE Trans. Antennas Propagat., Vol. AP-29, No.1, pp. 25-37, January 1981.

[3] Hyok Song J \& Marek Bailkowski E, Ku-Band 16×16 planar array with aperture-coupled microstrip patch elements, IEEE Antenna Propag Mag(USA), 40 (1998) 25 .

[4] Walcher D A, Lee R Q \& Lee K, Ku-band microstrip antenna, receiving array, Microw Opt Technol Lett (USA), 13 (1996) 213.

[5] A. Abbaspour-Tamijani and K. Sarabandi, "An affordable millimeter-wave beam steerable antenna using interleaved planar subarrays," Antennas and Propagation, IEEE Transctions on, vol. 51, pp-2193-2202, 2003.

[6] Konda R B, Pushpanjali G M, Mulgi S N, Satnoor S K, Hadalgi P M \& Hunagund P V, Design of wideband and multiband microstrip array antennas, Indian $\mathrm{J}$ Radio Space Phys, 35 (2005) 372.

[7] Mallikarjun S L, Madhuri R G, Malipatil S A \& Hadalgi P M, Development of microstrip array antennas for wideband and multiband applications, Indian $\mathrm{J}$ Radio Space Phys,38 (2009) 289.

[8] Maci S, Gentili G B, Dual-Frequency Patch Antennas, IEEE Antennas and Propagation Magazine, Vol. 39, No. 6, 1997.

[9] Lee Kai Fong, Weichen. Advances in Microstrip and Printed Antennas (John Wiley, New York), 1997. 